\title{
A Study of Composition of the Geopolymer Concrete Structure Using Silica Fume
}

\author{
${ }^{1}$ Nagraj Jammi, ${ }^{2}$ Krishna Rao.A \\ ${ }^{\text {I}}(P G$ Scholar, Department of Civil Engineering, CMR Institute of Technology, Hyderabad, India) \\ ${ }_{2}^{2}$ (Professor, Department of Civil Engineering, CMR Institute of Technology, Hyderabad, India)
}

\begin{abstract}
The usage of Portland cement in the process of concrete construction is under critical supervision due to release of enormous amount of carbon dioxide gas into the atmosphere during the production of cement. In recent times, an attempt has been made to enhance the utilization of silica fume in order to replace Portland cement partially in the concrete. Thus, Geopolymer concrete is considered to be the new material that does not require the presence of Portland cement as a binder. Instead, the source of the materials like Silica Fume that are rich in Silicon is activated by alkaline liquids in order to produce the binder. Hence, the resultant concrete will be free from Portland cement. This paper mainly presents the details of development of the process of making silica fume-based geopolymer concrete in order to avoid Portland cement partially.
\end{abstract}

Keywords: Binder, Concrete, Geopolymer, Portland cement and Silica fume.

\section{Introduction}

In general, a Concrete is considered to be as an artificial engineering material which is made by mixing Portland cement, water, fine and coarse aggregates and a small amount of air. It is the most widely employed construction material in the world. Concrete is the only major building material that can be transferred to the job site in plastic state. This unique feature makes the concrete as a desirable building material as it can be molded to any shape. Concrete provides wide latitude in surface textures and colors. It can be used further to construct a wide variety of structures like highways and streets, bridges, dams, large buildings, airport runways, irrigation structures etc. On the other hand, concrete has better strength, much economical and durable as well. Depending on the mixture of materials used, concrete will support, in compression. The durability of concrete is evidenced by the fact that concrete columns built by the Egyptians several years ago are in standstill position till today.

Concrete is used as a premier construction material and most widely used in all types of construction works like infrastructure, low and high-rise buildings, and domestic developments. It is one of the man-made products, essentially consisting of a mixture of cement, aggregates, water and admixture. Inert granular materials such as sand and crushed stone will form the major part of the aggregate. These materials are blended in required proportions in accordance with the strength parameter and Grade of concrete material. The major constituents of the conventional concrete by volume are coarse and fine aggregates, typically natural quarried stone or sand. The aggregates are formed into a concrete matrix followed by the addition of water and a binder such as Ordinary Portland Cement. The production of Portland cement binder has already been recognized as source of significant environmental damage as source of $\mathrm{CO}_{2}$ emissions worldwide.

The manufacture of Portland cement clinker involves the calcination of calcium carbonate according to the reactions:

$$
\begin{aligned}
& 3 \mathrm{CaCO}_{3}+\mathrm{SiO}_{2} \rightarrow \mathrm{Ca}_{3} \mathrm{SiO}_{5}+3 \mathrm{CO}_{2} \\
& 2 \mathrm{CaCO}_{3}+\mathrm{SiO}_{2} \rightarrow \mathrm{Ca}_{2} \mathrm{SiO}_{4}+2 \mathrm{CO}_{2}
\end{aligned}
$$

In order to reduce further the $\mathrm{CO}_{2}$ emissions which are associated with the concrete, a geopolymer material is used as it is considered to be a better alternative. Geo-polymer materials usually represent as one of the innovative technology that generates huge amount of interest in the construction industry especially considered as a sustainable material. The geopolymer can be in the form of -Si-O-Al-O- or -Si-O-Al-O-Si-O- or -Si-O-Al-O-SiO-Si-O respectively.

From the awareness created pertaining to the reduction of the cement content in concrete many countries tried many permutations and combinations in order to replace cement with different pozzoloniac materials. Some of the countries which took initiative for the production of Geopolymer concretes are depicted in Table 1. 
Table. 1 Worldwide status of Geopolymer concrete

\begin{tabular}{|c|c|c|}
\hline Country & Production yield in Tons & \% of World Production \\
\hline UK & 21565700 & 34.9 \\
\hline Australia & 15667600 & 25.4 \\
\hline India & 10148000 & 16.4 \\
\hline Brazil & 1973370 & 3.2 \\
\hline China & 1380980 & 2.2 \\
\hline Vietnam & 1128500 & 1.8 \\
\hline Mexico & 1004710 & 1.6 \\
\hline Japan & 2099000 & 3.4 \\
\hline
\end{tabular}

\section{Materials Required For Geopolymer Concrete:}

\section{(a) Cementitious binder:}

Various industrial by-products and naturally available materials can be used to produce geopolymer concrete. Commonly used cementitious binders are fly ash, silica fume, rice husk ash, etc.

\section{(b) Alkaline activators:}

Alkaline activators are the vital ingredient of geopolymer mix as it undergoes geopolymerization and gives binding property by igniting the $\mathrm{Al}$ and $\mathrm{Si}$ present in the cementitious binder. It mainly utilizes the high proportion of $\mathrm{pH}$ activators like combination of sodium hydroxide or potassium hydroxide and sodium silicate or potassium silicate.

\section{(c) Aggregates:}

Aggregates used to produce geopolymer concrete to be chosen and tested as per International standards.

\section{(d) Super plasticizer:}

This is used in concrete to either accelerate or decelerate the setting time and also to attain better workability conditions in a concrete.

The Geopolymer Concrete Mix Was Prepared As Follows:

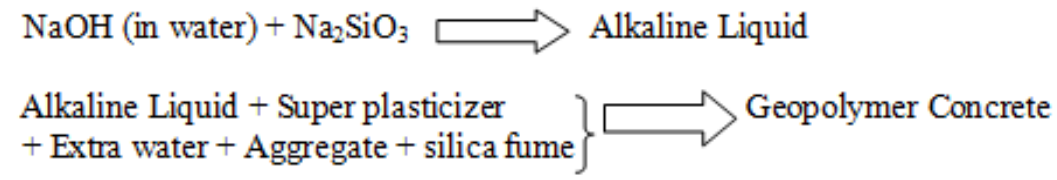

\section{Literature Review On Mix Design}

Davidovits.J et. al [1], used ground blast furnace slag to produce geopolymer binders. According to their research findings, Geopolymers were found to be fire resistant and durable under UV light. Joseph Davidovits [2], proposed a new type of concrete without Portland cement which is termed as geopolymer concrete. Geopolymer is an inorganic alumina-silicate polymer which is synthesized predominantly from silicon ( $\mathrm{Si})$ and aluminum (Al) material of geological origin. The chemical composition of geopolymer materials is similar to that of zeolite. Van Jaarsveld $\mathrm{J}$ et. al [3], has carried out their experiments on geopolymers using two types of fly ash. Palomo A et. al [4], basically studied about the influence of curing temperature, curing time and alkaline solution-to-fly ash ratio on the compressive strength. $\mathrm{Xu} \mathrm{H}$ et. al [5], investigated the geopolymerization of about ' 15 ' natural Al-Si minerals. It was found that the minerals with a higher extent of dissolution were demonstrated better compressive strength after polymerization. Swanepoel J.C et. Al [6] has conducted a study on geopolymers produced by mixing fly ash, kaolinite, sodium silica solution, $\mathrm{NaOH}$ and water.

Buchwald A et. al [7], studied about evaluation of different raw materials in which ecological and economic aspects were implemented and examined. Most of the literature focuses on mix design of Geopolymer concrete. Geopolymer concrete is having a denser structure and is expected to perform better under adverse environment. 


\section{Silica Fume Production}

The American Concrete Institute (ACI) defines silica fume as "very fine non-crystalline silica produced in electric arc furnaces as a by-product of the production of elemental silicon or alloys containing silicon". It is usually a gray coloured powder and is similar to portland cement or some fly ashes. This can be called as silica fume or micro silica. Fig. 1 given below basically shows a typical silica fume production process.

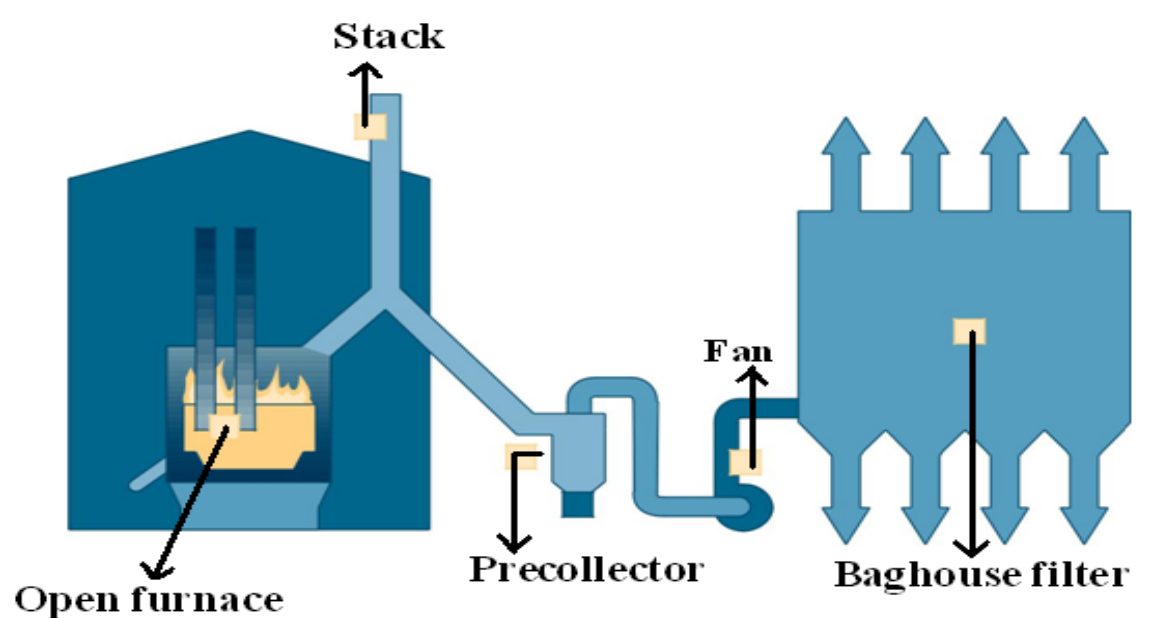

Fig. 1 Silica Fume Production

During the last few decades, new Pozzolan materials have been emerged in the building industry as an off shoot of research which basically aimed at energy conservation and strict enforcement of pollution control measures to stop dispersing of the materials into the atmosphere. Micro Silica is one such type of Pozzolana, which has been used as a partial replacement of Portland cement due to its versatile properties. The availability of high range water-reducing admixtures has opened up new ideas for the usage of Micro Silica as one of the cementing material in concrete to produce very high strength cement. Micro Silica is a by-product from the reduction of high purity quartz with coal in electric arc furnaces in the manufacture of silicon and ferrosilicon alloys. The micro silica, which has a high content of amorphous $\mathrm{SiO}_{2}$ which consists of very fine spherical particles, is collected from the gases escaping from the furnaces. The chemical properties of silica fume include Amorphous, Silicon dioxide and other trace elements which depend mainly on the type of fume. Table. 2 represent the physical properties of Silica Fume.

Table. 2 Physical properties of Silica Fume

\begin{tabular}{|l|l|}
\hline \multicolumn{2}{|c|}{ Physical properties of silica fume } \\
\hline Particle size (typical): & $<1 \mu \mathrm{m}$ \\
\hline Bulk density (Densified): & 480 to $720 \mathrm{~kg} / \mathrm{m}^{3}$ \\
\hline Specific gravity: & 2.2 \\
\hline Specific surface area : & 15,000 to $30,000 \mathrm{~m}^{2} / \mathrm{kg}$ \\
\hline
\end{tabular}

The composition of silica fume is shown below in Table. 3 .

Table. 3 Composition of Silica Fume

\begin{tabular}{|l|l|l|}
\hline S.No & Constituents & Percentage \\
\hline 1 & Silica, $\mathrm{SiO}_{2}$ & 92.00 \\
\hline 2 & Alumina, $\mathrm{Al}_{2} \mathrm{O}_{3}$ & 0.46 \\
\hline 3 & Iron Oxide, $\mathrm{Fe}_{2} \mathrm{O}_{3}$ & 1.60 \\
\hline 4 & Lime, $\mathrm{CaO}$ & 0.36 \\
\hline 5 & Magnesia, $\mathrm{MgO}$ & 0.74 \\
\hline 6 & Sulphur Trioxide, $\mathrm{SO}_{3}$ & 0.35 \\
\hline 7 & Loss on ignition & 2.50 \\
\hline 8 & $\mathrm{Na}_{2} \mathrm{O}$ & 0.70 \\
\hline 9 & $\mathrm{~K}_{2} \mathrm{O}$ & 0.90 \\
\hline 10 & $\mathrm{P}^{\mathrm{H}}$ & 7.60 \\
\hline 11 & Accelerated Pozzolonic Acidity index in 7 days & 104.00 \\
\hline 12 & Accelerated Pozzolonic Acidity index in 28 days & 117.00 \\
\hline 13 & Surface Area m ${ }^{2} / \mathrm{kg}$ & 18.9 \\
\hline 14 & Moisture Content & 1.00 \\
\hline 15 & Bulk Density & $450-650$ \\
\hline
\end{tabular}


Advantages Of Geopolymer Concrete

A Geopolymer concrete which is termed as silica fume, offers a number of benefits over conventional Ordinary Polymer Concrete including:

- Significantly lower $\mathrm{CO} 2$ emissions.

- Better thermal insulation properties.

- Higher temperature/fire resistance.

- Provides a viable use for 'waste' materials which are often disposed in landfill.

- Better compressive strength.

\section{Conclusion}

The main focus of this paper is to assess the utility of silica fume as a geopolymer concrete as an alternative to the ordinary Portland cement concrete. The properties of materials have to be known before it can be used as an alternative of ordinary concrete. Thus, this paper explained about the various chemical and physical compositions of silica fume. This study focuses on replacement of normal cement with silica fume which is termed to be as geopolymer concrete. The future scope of this work may be focused on performing different feasibility tests like slum tests, Split tensile test, ultrasonic pulse velocity test, water penetration test and thereby performing finite element analysis using ANSYS software. Thus, efficacy as well as composition of silica fume can be investigated further by performing the aforementioned tests.

\section{References}

[1]. Davidovits J and Sawyer J L [1], J. Chemistry of Geopolymeric Systems, Terminology. Geopolymer '99 International Conference. France: 1999.

[2]. Joseph Davidovits [2], Geopolymer chemistry and application, Geopolymers Institute, ISBN 2-651-4820-1-9, 2008

[3]. Van Jaarsveld J GS, Van Deventer J S J and Schwartzman A[3], The potential use of Geopolymeric Materials to Immobilise Toxic Metals:Part I. Theory and application, Minerals Engineering, Vol. 10, No. 7, pp. 659-669, 1997.

[4]. Palomo A, Grutzeck M W and BlancoM T [4], Effect of curing regime and type of activator on properties of alkali-activated fly ash, 1st International Symposium on Nanotechnology in Const, 1999.

[5]. Xu H and Van Deventer J S J [5], The Geopolymerisation of AluminoSilicate Minerals, International Journal of Mineral Processing, Vol. 59, No. 3, pp. 247-266, 2000.

[6]. Swanepoel J C and StrydomC A [6], Utilisation of fly ash in a geopolymeric material. Applied Geochemistry, Vol. 17: pp. 11431148, 2002.

[7]. Buchwald A, Dombrowski and Weil A [11], Geopolymer Technology: The Current State Of The Art, Journal of Material Science, Vol. 42, pp. 2917-2933, 2007. 